\title{
VALORES Y EMPRESA: EL PAPEL DEL PLURALISMO *
}

\author{
Eusebio Fernández \\ Universidad Carlos III
}

RESUMEN. El presente artículo tiene como objetivo el reflexionar acerca de algunos valores morales que se considera deben servir de guía en ese conjunto de relaciones sociales que crean las empresas. No se trata, por tanto, de elaborar criterios externos al marco del desarrollo de las empresas, sino de partir de la vida y el lenguaje empresarial con el fin de evaluarlas moralmente. La ética empresarial tiene un campo de actuación más amplio que el del derecho, al mismo tiempo que no goza de su eficacia, pero tampoco se trata, solamente, de buenas intenciones o consejos de decencia pública. La importancia de la autonomía, la libertad, la responsabilidad, la confianza, la necesidad de buenas leyes, la seguridad, la buena fe o la profesionalidad son los contenidos básicos y plurales de la ética de empresa.

Palabras clave: valores morales, ética empresarial, decencia pública, pluralismo.

ABSTRACT. The purpose of this article is to reflect on some of the moral values that are meant to guide the set of social relations created within companies. This is, therefore, not about establishing criteria external to the framework around which companies develop, but rather observing companies' life and business language in order to evaluate it morally. The field of business ethics is broader than the legal field but lacks its efficacy. It also does not deal solely with good intentions and public decency. The importance of autonomy, liberty, responsibility, trust, the need for good laws, security, good faith and professionalism compose the basic and multiple contents of business ethics.

Keywords: moral values, business ethics, public decency, pluralism.

* Fecha de recepción: 7 de noviembre de 2011. Fecha de aceptación: 18 de diciembre de 2011. 
M

e corresponde disertar acerca de la ética de la empresa y el pluralismo. De entrada, la una, como parte de una ética cívica o como aplicación de sus propuestas y directrices al ámbito de la organización de las empresas, y el otro, como descripción de la existencia de diversidades en el plano de las concepciones del mundo, de la vida, pero también como toma de postura moral que valora positivamente esa diversidad, no tienen por qué estar conectadas necesariamente. Cabría por tanto una ética aplicada a la empresa sin contenidos plurales y negando de base la deseabilidad de admitir el pluralismo moral. Pero aquí voy a mantener la necesidad y la mayor corrección de la postura contraria. Por tanto, los contenidos de la ética de la empresa elegida son plurales, es decir, no uniformes, parten de sociedades plurales y prefieren tener como objetivos morales el mantenimiento del pluralismo moral. Nada que ver por tanto con absolutismos morales, aunque algunos de sus contenidos gozan de mayor permanencia y estabilidad que otros, Y nada tiene que ver con el relativismo moral, concepción que incluiría la postura de que en moral todo vale o todo vale igual. No, la ética, materia en la que debatimos, comparamos, preferimos y elegimos con suficiente libertad y, por tanto, responsabilizándonos de la conducta realizada, es incompatible con el relativismo moral. Lo que significa que la apuesta por el pluralismo moral, del que tanto I. BERLIN o J. RaWLS nos han enseñado, consta de un abanico amplio de opciones, pero no de todas las posibles.

Me parece que la pregunta por la viabilidad y utilidad de la ética empresarial no debe separarse de la de su necesidad y deseabilidad. Y una manera de poder pasar de la necesidad a la utilidad y la deseabilidad, a través de la viabilidad, es debatir éticamente al mismo nivel de la vida interna y funcionamiento de las empresas. Lo que equivale a decir que el lenguaje ético y el lenguaje empresarial deben entenderse entre sí. Como ocurre o debe ocurrir, también entre el lenguaje de la ética y el de la política. Como ha señalado J. M. LOZANO, «se trata de hacer propuestas éticas que asuman una perspectiva ética, pero que sean capaces de hablar críticamente, si hace falta un lenguaje empresarial» ${ }^{1}$.

Esta advertencia metodológica es importante, además de constituir la vía adecuada para que la ética empresarial evite ser una ética de sermones y se erija como una ética realizable en el marco de una institución social, como es la empresa. La empresa, por influyente que sea su función en la vida cotidiana, además de abarcar elementos amplios y relevantes de ella, es un subcampo de otro más grande poblado por las organizaciones e instituciones sociales. Y ello significa, por principio, que la ética empresarial es una ética aplicada que forma parte de la ética social y económica o, para concretar más, de una ética cívica, es decir de una ética por y para los ciudadanos que viven en un determinado marco histórico y que hoy, de manera inexcusable está constituida, principalmente, por virtudes y derechos (ética de las virtudes más ética de los derechos). Además, la ética empresarial debe convivir con el derecho de una sociedad sin confundirse con él, pero no dándole la espalda, ya que algunas normas éticas no deben transformarse en normas jurídicas, pero otras sí lo hacen. En todo caso, la vivencia de las normas morales sirve para reforzar la eficacia de las normas jurídicas y a la inversa.

1 J. M. LOZANO, Ética y empresa, Madrid, Trotta, 1999, 9. 
Otro dato importante para tener en cuenta es que una ética empresarial, como ética cívica aplicada, si quiere mantenerse fiel a la divisa pluralista, debe considerar la diversidad y heterogeneidad de las teorías éticas existentes, entendida aquí como códigos éticos, para examinar, y por tanto optar, por lo que hay de aprovechable y recomendable en cada una de las éticas normativas, priorizando la viabilidad de su aplicación al mundo de la empresa. Ello equivale a admitir que, previamente a la constitución de los contenidos de la ética empresarial, existe una discusión y una opción política de carácter más general que no podemos soslayar. No es asunto baladí para la ética de la empresa que seamos más o menos liberales en el ámbito económico, socialdemócratas e intervencionistas, comunitaristas o republicanos, por referirme a algunas de las más patentes teorías de filosofía política. Además, poco haremos en la construcción de una ética de y para la empresa si previamente no nos hemos aclarado sobre la bondad y la justicia de nuestras acciones, los deberes morales que originan y el lugar que ocupan sus destinatarios que al hablar de moral y justicia, necesariamente abarcan a la humanidad en su totalidad, aunque se realizan en marcos culturales, tradiciones históricas y geográficas más reducidas. El tener en cuenta los intereses de todos los afectados por nuestras acciones se convierte así, en un lema básico de la ética.

Y al ser la empresa un multiforme lugar social donde no sólo se ejercen derechos sino que se producen, intercambian y comparten valores, se convierte también en un espacio de debate y discusión moral en el que aparecen comprometidos todos los sujetos que tienen que ver con ella.

A veces es preferible, además de admisible y adecuado, cambiar de perspectiva y métodos a la hora de enfrentarnos al debate y análisis de cuestiones importantes para la convivencia humana (y, por supuesto para el conocimiento y el progreso de la ciencia). Y ello ocurre también, en el ámbito del tratamiento de las cuestiones de ética normativa y aplicada. Con frecuencia dedicamos demasiados esfuerzos a los temas de carácter metaético, en detrimento de lo más urgente en el plano de las soluciones éticas a los conflictos sociales. Generalmente, las ramas del antipático relativismo y del orgulloso subjetivismo impiden ver con claridad las dimensiones del bosque.

Y quizá una manera eficaz de no sucumbir a algunas discusiones estériles en la reflexión moral, y de aparcar el escepticismo, sea invertir el mecanismo de acercamiento a las cuestiones éticas. Si a lo largo de la historia de la filosofía moral la reflexión y el debate ético que ha caracterizado a las distintas corrientes se ha dedicado a plasmar su idea del bien y de lo bueno, a fundamentarlo y a aplicarlo, modelando así la vida personal y las instituciones sociales, ahora se trata de partir de la existencia del mal, del daño y de las desgracias humanas para posibilitar que se vea mejor la necesidad ineludible del bien. Es posible que, en un primer momento, sea más fácil compartir la idea de lo que es abiertamente inhumano, perjudicial o injusto que sus contrarios. Esta vía negativa de acercamiento a los problemas éticos es útil, aunque insuficiente para los cultivadores más exigentes de la ética.

K. POPPER, hace ya bastantes décadas, insistió en su oportunidad al señalar en $L a$ sociedad abierta y sus enemigos: «Se aclara el campo de la ética si formulamos nuestras 
demandas negativamente, es decir, si pedimos la eliminación del sufrimiento más que la promoción de la felicidad» ${ }^{2}$.

Y más recientemente $S$. BLACKBURN, en una obra introductoria a la ética, ha indicado: «Otra aproximación posible al problema de la buena vida consiste en plantearnos qué es lo que debemos evitar. Para empezar, resulta mucho más fácil ponerse de acuerdo sobre esta lista... Siempre ha sido más fácil decir en qué consiste el infierno que en qué consiste el cielo» ${ }^{3}$.

Voy a ser fiel a la utilización de esta vía negativa. Por ello voy a partir de la referencia a tres casos acaecidos recientemente, que son objeto de una indignación moral fácilmente compartida, con el propósito de atajar, de esa manera, la cuestión de la necesidad de una ética empresarial. Su contenido y fundamentación ya son objeto, como creo que se pueda ver, de una vía positiva.

En el análisis, efectuado por M. J. SANDEL en su exitoso y celebrado libro Justicia. ¿Hacemos lo que debemos? ${ }^{4}$, de un conjunto de casos contemporáneos que exigen una valoración ética por su trascendencia social hallamos, al menos, dos que afectan directamente a las cuestiones pertinentes de la ética empresarial. Se trata, el primero de ellos, de los precios abusivos exigidos por parte de un número de comerciantes a la población necesitada de ciertos servicios, como consecuencia de la devastación producida por el huracán Charley, verano de 2004, a su paso por Florida, y que tuvo como consecuencias más puntuales la muerte de veintidós personas y unos daños materiales que ascendieron a 11.000 millones de dólares. Como ejemplos, podemos quedarnos con los siguientes: «En una gasolinera de Orlando vendían a diez dólares las bolsas de hielo que antes costaban dos. Como no había energía eléctrica para las neveras o el aire acondicionado, a muchos no les quedó otro remedio que pagar. Los árboles derribados aumentaron la demanda de motosierras y reparaciones de tejados. Por retirar dos árboles del tejado de una casa se pidieron 23.000 dólares. Las tiendas que vendían pequeños generadores domésticos de electricidad por 250 dólares querían ahora 2.000 . A una mujer de setenta y siete años que huía del huracán con su anciano marido y una hija discapacitada le cobraron 160 dólares por noche por una habitación de motel, cuando normalmente cuesta $40 »^{5}$.

Como no podía ser de otra manera, el asunto produjo acaloradas discusiones en los medios de comunicación, que dieron lugar a un interesante debate acerca de los precios abusivos en situaciones tan dramáticas como las señaladas. En dicho debate salieron a flote importantes cuestiones donde se aducía desde los límites a la avaricia humana y la justificación o no de la actuación de los poderes públicos en circunstancias excepcionales, hasta el alcance de las reglas del libre mercado, la competencia y el éxito empresarial. No cabe ninguna duda sobre la oportunidad de plantearse cuestiones de

2 K. Popper, The Open Society and Its Enemies, London, Routledge \& Keagan Paul, vol. I, 1962, 285.

3 S. Blackburn, Sobre la bondad. Una breve introducción a la ética, Barcelona, Paidós, 2002, 149. Vid. también E. Garzón Valdés, Propuestas, Madrid, Trotta, 2011, 344 y ss. Coincido con su apreciación de «que puede admitirse que es más fácil comprobar una actitud universal de rechazo del mal absoluto más que de coincidencia acerca de lo bueno absoluto», 348. Gómez.

${ }^{4}$ M. J. SANDEL, Justicia. ¿Hacemos lo que debemos?, Barcelona, Debate, 2011, traducción de J. P. CAmpos

$$
5 \text { Ibid., } 11 .
$$


este tipo: «¿está mal que los vendedores de bienes y servicios saquen partido de un desastre natural cobrando tanto como el mercado pueda soportar? Si está mal, ¿Qué debería hacer la ley al respecto, si es que debe hacer algo? ¿Debe prohibir el Estado las subidas especulativas de precios incluso si con ello, interfiere en la libertad de compradores y vendedores de cerrar los tratados que deseen» ${ }^{6}$.

El segundo ejemplo tiene que ver con el rescate bancario, decidido por el Gobierno y el Congreso de los Estados Unidos para aminorar las consecuencias negativas de la crisis financiera de 2008-2009.

Los hechos son los siguientes: «La rabia pública por la crisis financiera de 20082009 viene aquí a cuento. Durante años, los precios de las acciones y de la propiedad inmobiliaria habían estado subiendo mucho. El día del juicio llegó cuando reventó la burbuja inmobiliaria. Los bancos e instituciones financieras de Wall Street habían ganado miles de millones de dólares gracias a complejas inversiones respaldadas por hipotecas, pero su valor cayó en picado. Las antes orgullosas firmas de Wall Street se balanceaban ahora al borde del abismo. El mercado bursátil se hundió, y arrastró consigo no solo a los grandes inversores, sino a los estadounidenses corrientes, cuyos planes de pensiones perdieron buena parte de su valor. La riqueza total de las familias estadounidenses disminuyó en 2008 en once billones de dólares, cantidad igual a la producción anual de Alemania, Japón y el Reino Unido juntos.

En octubre de 2008, el presidente George W. Bush pidió al Congreso 700.000 millones de dólares para rescatar a los grandes bancos y entidades financieras de la nación. No parecía equitativo que Wall Street gozase de beneficios enormes en los buenos tiempos y que ahora que las cosas iban mal pidiera a los contribuyentes que pagasen la factura. Pero no parecía haber otra salida. Los bancos y demás entidades financieras habían crecido tanto y habían llegado a influir hasta tal punto en cada aspecto de la economía que su hundimiento habría arrastrado consigo al sistema económico entero. Eran "demasiado grandes para caer" $\gg$.

Pero la discutida, aunque parece que imprescindible, concesión de los fondos para el rescate, pagados con cargo a los contribuyentes fue seguida de otra iniciativa, ya no decidida por la Administración, que consistió en el pago de primas que algunas de las entidades favorecidas por el rescate entregaron a sus ejecutivos. La indignación y las protestas públicas, como es perfectamente lógico, no se hicieron esperar. Difícilmente es posible encontrar alguna justificación moral a tal tomadura de pelo. Ni ningún punto de vista sobre la justicia parece permitir el pago de esas primas con cargo, al fin y al cabo, al dinero público, como respuesta a fracasos generados por la irresponsabilidad y la avaricia.

¿Es correcto premiar de esta manera la codicia? ¿Está permitida moralmente la indiferencia frente a la avaricia cuando van bien las cosas y se logran preciados éxitos económicos y la indignación cuando las cosas se tuercen, dando lugar a resultados económicos y sociales desastrosos? ¿Dónde se halla la diferencia, en nuestras convicciones morales o en actitudes sociales condicionadas culturalmente?

M. SANDEL plantea con claridad este conflicto moral: «Tras la indignación por el rescate - señala - había una creencia sobre el merecimiento según el punto de vista

${ }^{6}$ Ibid., 14.

7 Ibid., 21 y 22. 
de la moral: los ejecutivos que recibieron las primas no se las merecían, como tampoco el rescate las firmas a las que salvó. Pero ¿por qué no? La razón podría ser menos evidente de lo que parece. Piénsese en dos respuestas posibles, una que se refiere a la codicia y la otra al fracaso».

Y aduce un hecho incontestable: «La gente se indignó en 2008 cuando las entidades de Wall Street (algunas de las cuales, si existían todavía, era sólo gracias al respaldo económico de los contribuyentes) entregaron 16.000 millones de dólares en primas. Pero esta cifra no era ni la mitad de la que pagaron en 2006 (34.000 millones) y 2007 (33.000 millones). Si la codicia es la razón de que no se merezcan ahora el dinero, ¿Qué razón puede haber para decir que se lo merecían entonces?».

Para concluir: «La verdadera objeción de los estadounidenses a las primas - y al rescate - no es que recompensen la codicia, sino que premien el fracaso. Los estadounidenses son más duros con el fracaso que con la codicia» ${ }^{8}$.

Deseo pensar que en el marco europeo, y en el español, esa conclusión hace un momento señalada, iría acompañada de objeciones, o, al menos, importantes matizaciones. Pero lo que aquí ahora me interesa es resaltar que han aparecido ya términos morales convencionales en la discusión secular sobre la justicia como merecimiento, premiar o codicia. Además podríamos complicar el debate planteado, y que hasta ahora se ha centrado en buscar los motivos de la falta de justificación moral o de merecimiento del rescate y el pago de las primas en la cabal respuesta a la codicia y/o al fracaso, introduciendo la posibilidad de que el no merecimiento del rescate y las primas sea el resultado de la irresponsabilidad moral $^{9}$, la falta de prudencia o la simple indecencia. En todo caso, la corrección de nuestras valoraciones morales no se puede hacer depender de que corran buenos o malos tiempos para el mercado, sino de la respuesta a la pregunta de si cabe plantear la existencia de limitaciones morales a la existencia y a las consecuencias sociales del libre mercado. Y me parece que es del todo pertinente mantener la distinción del mercado como modo de producción del mercado como modo de distribución de bienes sociales.

Este verano de 2011, además, nos ha traído un nuevo caso para permitirnos reflexionar sobre la ética empresarial en una sociedad libre. Se trata del escándalo de las escuchas ilegales llevadas a cabo por parte de medios de prensa del grupo Murdoch. $\mathrm{El}$ caso, además, ha salpicado al propio sistema político y económico británico y a los miembros de la policía, sacando a la luz muchos elementos inmorales que, a pesar de su evidente deshonestidad han contado durante mucho tiempo con el acompañamiento del éxito y del beneficio.

La indignación que estos hechos han provocado en la sociedad, ¿es simple rencor u odiosa envidia o va más allá? Creo que el asunto no solamente puede llegar a estimular las bajas pasiones en la gente. Me parece que además son prueba de irritación moral sincera que araña y remueve las bases de la idea de una sociedad decente y justa. La ética no solamente es debate, análisis y reflexión racional sobre lo razonable moralmente. Creo que nos equivocamos si no admitimos en el ámbito ético el papel

8 Ibid., 24 y 25.

9 Recomiendo la lectura del trabajo de E. GARZÓN VALDÉS, «El enunciado de responsabilidad», incluido en su reciente libro Propuestas, op. cit., 155 y ss. 
esencial que ejercen el carácter, el ánimo, los sentimientos o las pasiones. Como nos ha recordado en un libro reciente V. CAMPS «no hay razón práctica sin sentimientos» $\mathbf{y} \ll \mathrm{El}$ gobierno de las emociones es el contenido de la ética» ${ }^{10}$. La respuesta indignada del que observa o sufre las inmoralidades de la libertad empresarial mal entendida no solo es expresión de emotividad, es también un acto de moralidad propio de cuidadanos decentes, responsables y con una idea de justicia que trasciende sus propios intereses y derechos.

Cabe preguntarse si los tres ejemplos presentados aquí son una demostración de lo adecuado de la idea de que la ética es rentable para la empresa. Ojalá así fuera, aunque habría que añadir que su campo de verificación está más cercano del medio y largo plazo que a corto plazo.

Parece, por tanto, que existen buenas razones, de argumentación y de justicia, para hablar de criterios y limitaciones morales aplicables al ámbito empresarial. Sin embargo, no cabe la satisfacción de una respuesta afirmativa sin añadir cuáles deber ser esos criterios y límites morales y con qué fundamentación cuentan, preguntas siempre pertinentes cuando nos adentramos en el ámbito de las éticas normativas y aplicadas.

La rentabilidad de la ética para la empresa no hay que tomarla en un sentido literal, lo que significaría estar abogando por la mercantilización de la ética. La rentabilidad a la que hemos de referirnos es la rentabilidad de la responsabilidad moral, la que deriva de la exigencia de autonomía y libertad. Es la responsabilidad que exige asumir deberes y obligaciones y no sólo la reivindicación de derechos. Es la conjunción de la ética de las virtudes con la ética de los derechos. Probablemente sólo esa responsabilidad constituya el mecanismo capaz de crear confianza, algo tan imprescindible en el ámbito de la empresa, como en el de la economía o la política. La confianza es un sentimiento social fuerte que no se puede lograr a golpe de legislación, aunque, sin duda, las buenas leyes dan seguridad y generan confianza.

Autonomía, libertad, responsabilidad, confianza, buenas leyes, seguridad... pronto van apareciendo los ejes claves para edificar y mantener cualquier ética de la empresa.

Además, teniendo en cuenta que en el marco de una empresa se integran y desarrollan elementos con vida propia, como son el capital, el mercado, la competencia, la creación de productos, la satisfacción de necesidades humanas, el trabajo o el beneficio y que crean entre sí relaciones sociales más o menos estables, harán presencia inmediatamente otros valores para ordenarla y regularla adecuadamente. Así, a manera de ejemplo, según un estudioso veterano de estos asuntos, J. L. FERNÁNDEZ FERNÁNDEZ: «Servicio al cliente, pasión por la calidad, respeto a las personas dentro de la organización, búsqueda de la excelencia, colaboración con el Estado, acatamiento de la legalidad, cuidado del medio ambiente, comportamiento cívico y preocupación por las responsabilidades sociales de la empresa, justicia en las relaciones bilaterales con los proveedores y distribuidores, fe en el limpio juego del mercado y apuestas por una sana y libre concurrencia, que respete los derechos de los competidores. Tales son algunas de las divisas que parecen estar asumiendo muchas empresas en sus políticas y planes de negocio» ${ }^{11}$.

\footnotetext{
10 V. CAMPs, El gobierno de las emociones, Barcelona, Herder, 2011, 13 y 14.

11 J. L. FERNÁNDEZ FERNÁNDEZ, Ética para empresarios y directivos, Madrid, Esic Editorial, 1994, 17.
} 
Pero conviene advertir de y resaltar algunos presupuestos teóricos y máximas metodológicas de interés, para que nuestro quehacer no se desarrolle por caminos inapropiados. Podemos señalar algunos ejemplos al respecto. Así, no debe olvidarse que el beneficio, aunque no tenga por qué ser el único objetivo de una empresa, sí es un fin esencial a su existencia. Una empresa no es una institución de caridad, ni debe actuar como tal. Ganar dinero entra entre los fines legítimos de una empresa. Sin embargo, lo que también es legítimo desde una perspectiva ética es plantearse cómo se gana y si ello repercute negativamente en otros valores sociales relevantes. De la misma manera que existen medios eficaces e inútiles, se dan medios decentes ${ }^{12} \mathrm{e}$ inadecuados desde el punto de vista ético.

También, en el marco de las prácticas correctas e incorrectas desde el punto de vista ético, se debe evitar caer tanto en posturas minimalistas como maximalistas. Las primeras son las que reducen el análisis y valoración ética a lo jurídicamente permitido. Las segundas son las que intentan que el derecho abarque e integre todas las exigencias éticas significativas en una sociedad. En ambos casos se está confundiendo la moral y el derecho, sin tener en cuenta las distinciones y separaciones entre el ámbito moral y el ámbito jurídico que toda sociedad libre, abierta y plural requiere. En este tipo de sociedad es lógico que la ética sea más exigente que el derecho, aunque éste siempre recoja contenidos éticos básicos. De alguna manera se podría indicar que la ética empresarial, como toda ética aplicada, se mueve en un área que nunca pertenece exclusivamente a la moral ni al derecho, pero se alimenta de la una y del otro. Así la confianza mutua, la lealtad, el cumplimiento de la palabra dada, la lucha contra el fraude, el respeto a los consumidores o la buena fe, presupuestos indudables de la vida empresarial decente, merecen la atención de la moral y del derecho, pero, salvo en lo que coinciden, lo hacen de manera diferente. Ese déficit moral de lo permitido jurídicamente quizá sea el precio necesario que debe pagar una sociedad compuesta por ciudadanos libres e iguales ante la ley. Y aquí la ética empresarial adolece de una característica que es común a todas las éticas de las profesiones. Y lo hace sobre todo teniendo en cuenta la terrible experiencia humana de aquellas sociedades que han intentado moralizar lo político y lo jurídico desde posturas dogmáticas y absolutistas o utilizar la intervención asfixiante del Estado totalitario. Los medios de humanizar la vida social y económica también deben ser calibrados y medidos. De lo contrario caerán en la peor ideologización política o en la hipocresía moral aguda.

¿Significa esto que una gestión moral de la empresa debe situarse, sin matices, en la ética de la responsabilidad y no en la ética de las convicciones, utilizando la distinción en el sentido weberiano? No necesariamente. Como he señalado en otro lugar, referido al marco de la política, siempre caben soluciones intermedias como es el caso de una ética de convicciones responsables ${ }^{13}$.

Y esa podría ser la situación de una ética empresarial que tenga como principios el respeto a la legalidad, la profesionalidad, la confidencialidad, la fidelidad y responsabilidad, la buena fe, el evitar conflictos de intereses o el respeto a la integridad de las personas ${ }^{14}$.

12 La utilización del calificativo decente que aquí aparece tiene que ver con las características a que se ha referido A. MARGALIT, La sociedad decente, Barcelona, Paidos, 2010, trad. de C. CASTELlS.

13 E. FernándeZ GarCía, Valores constitucionales y derecho, Madrid, Dykinson, 2009, 36.

14 J. L. FERNÁNDEZ FERNÁNDEZ, Ética para empresarios y directivos, op. cit., 181 
Hoy cualquier propuesta de ética social y económica debe incluir una parte esencial de ética de, para y en la empresa, pues son muchos aspectos de la vida cotidiana en los que interviene la empresa, tanto en el trabajo como en el ocio. El todo vale, si se producen beneficios, tiene un poder aniquilador muy claro y es una fuente de creación de actos de corrupción. Además, el mundo de la empresa debe estar sometido al imperio de la ley, y no de cualquier ley, sino de las que caben en el ámbito del Estado social y democrático de derecho que representa ya de por sí una opción ética inconfundible. Y estas exigencias morales no son incompatibles con la libertad a la hora de hacer negocios, con su rentabilidad, con la calidad de los productos, con la honradez, la creatividad, el reconocimiento del esfuerzo o mérito, la capacidad de iniciativa y los derechos de los empleados, proveedores y consumidores.

Si atajamos las cuestiones que plantea la ética empresarial con realismo, conocimiento y prudencia, evitando caer en la fácil «moralina», fiel aliada de la hipocresía, podremos entender el significado de la idea de que no se deben hacer negocios al margen de la ética y eliminar la desconfianza que los empresarios puedan tener hacia esta ética de mínimos que estoy propugnando ${ }^{15}$.

Tomando como base los distintos valores, principios y propuestas de acción correcta que han ido apareciendo a lo largo de la exposición y que constituirían el modelo y contenido axiológico de una ética normativa aplicable a la empresa, es el momento de preguntarse por su estatuto ontológico y epistemológico, es decir, por la manera más correcta de sustentarlas (validez y vigencia) y por la forma y alcance epistemológico de su defensa y los argumentos racionales que podríamos utilizar a su favor en un debate sobre ellos o a la hora de pretender solucionar un posible, y bastante probable, conflicto de valores.

Por contestar rápidamente a esos dos interrogantes. En primer lugar: estamos hablando de valores plurales, que pueden entrar en colisión entre sí y cuya existencia no cuenta con una validez absoluta, sino lastrada por la temporalidad, la tensión y la falta de armonía total entre ellas. En segundo lugar: la mejor manera de contar con un argumento sólido a la hora de justificar un valor, norma o solución a un conflicto valorativo es aplicar el principio kantiano de la universalizabilidad, o en una versión más simplificada: tener en cuenta los intereses de todos lo que se ven afectados por una propuesta, solución u opción.

Parece claro que no se debe insistir mucho en que el pluralismo moral (pluralismo descriptivo y pluralismo normativo) es difícilmente conciliable con el absolutismo moral, con su uniformidad y su orgulloso dogmatismo. Uno y otro olvidan la idea de historicidad de los seres humanos. Aunque, es necesario decirlo, el pluralismo moral no se olvida de la rotundidad moral y de la moderadamente flexible contundencia de ciertos valores como el respeto a la dignidad o valor de los seres humanos, es decir, su integridad física y moral, la seguridad, la autonomía, la libertad, la igualdad o la solidaridad. Lo que hace el pluralismo es recordarnos que la vigencia al mismo tiempo de todos esos valores no es totalmente armónica y absoluta sino que requiere que algunos

15 Algo de esto está señalado en mi aportación al libro colectivo de R. DE AsIS, E. FERNÁNDEZ, M. ${ }^{a}$ D. González Ayala, Á. Llamas y G. PECES-BARBA, Valores, derechos y Estado a finales del siglo XX, del que fui su editor y prologuista, Madrid, Dykinson, 1996, 145 y ss. 
de ellos, o parte de algunos de ellos, se vean limitados o sacrificados por la preponderancia de los otros. Y, al mismo tiempo, el pluralismo se sustenta en la creencia de que es prácticamente imposible hablar de valores válidos en todo tiempo y lugar, porque la historia y la cultura tienen mucho que decir al respecto y en sentido contrario.

Pero tampoco el pluralismo moral hace buenas migas con el relativismo. Le cuesta pensar que todos los valores se reduzcan a lo relativo del tiempo y lugar, que todo sea del color del cristal con que se mira o que todo vale igual, ya que cada valor o norma moral encuentra su justificación en la sociedad y en la cultura que los arropa y no nos están permitidas las comparaciones en términos morales. El pluralista moral suele tener en cuenta que, a pesar de la historicidad y la culturalidad de los valores, las distintas y diversas concepciones morales tienen elementos también comunes entre ellas y que éstos se pueden comprobar incluso en grandes unidades de espacio y tiempo. Y esa creencia es aún más sólida si comprobamos las coincidencias acerca del mal entre concepciones morales distintas, lo que anteriormente se ha denominado vía negativa de acercamiento a la moral.

El escéptico sobre todo esto haría bien, si quiere convencernos de la rigurosidad de sus opiniones, en plantearse, por ejemplo, si los contenidos, en derechos y deberes, de la Declaración Universal de Derechos Humanos de 1948, proclamada y aprobada por la ONU, supera el test de universalizabilidad o punto de vista universal (que, en ningún caso significa creer o expresar que sus contenidos han sido válidos y son válidos, en todo tiempo y lugar. El punto de vista universal, por tanto, es normativo y no descriptivo).

En resumen, un filósofo contemporáneo, autor de una interesante introducción a la filosofía moral, no ha estado desacertado al escribir sobre estas cuestiones: «Tiene que haber una vía intermedia entre las arenas movedizas del relativismo y las frías rocas del dogmatismo» ${ }^{16}$.

Y respecto a la fundamentación de los valores — todos en torno a la idea de justicia- que hemos de aplicar a las realidades y dinámica empresariales no nos sirve tampoco ni el absolutismo moral ni el relativismo. Parece más adecuada la postura del pluralismo valorativo, pero a partir de una ética de mínimos de carácter intersubjetivo y universalizable. Sin embargo, algunas teorías de la justicia contemporáneas han ido demasiado lejos en la distinción entre lo bueno y lo justo, quizá motivadas por la necesidad de que lo justo pueda recoger unos mínimos realmente compartidos entre visiones morales, culturas e ideologías distintas y, además, enfrentadas entre sí. Dudo de la conveniencia de exigir, sin matices, ese precio, que puede estar sacrificando aspectos esenciales de algunas concepciones de la justicia y que pueden ser enriquecedores de otras a ellas enfrentadas. Y siempre es mejor un debate vivo que la fría e insatisfactoria neutralidad de no querer entrar en los porqués.

Por ello, creo que le sobran razones a M. SANDEL cuando ha señalado: «El intento de desligar los argumentos sobre la justicia y los derechos de los argumentos sobre la vida buena es un error por dos razones: en primer lugar, no siempre se pueden zanjar las cuestiones referentes a la justicia y a los derechos sin resolver cuestiones

\footnotetext{
16 S. BlackBuRn, Sobre la bondad. Una breve introducción a la ética, op. cit., 50.
} 
morales sustantivas; y en segundo lugar, incluso cuando es posible, puede que no sea deseable» ${ }^{17}$.

En definitiva, abundan argumentos teóricos, pero también de oportunidad y de utilidad, para mantener la continuidad entre la filosofía moral y las filosofías política y jurídica ${ }^{18}$. Y ese es el ámbito adecuado, me parece, para tratar las cuestiones referentes a la ética empresarial.

La ética empresarial debe utilizar simultáneamente, y recaer en, una doble vía: la personal y la institucional. Cualquiera de las dos, independiente de la otra, resultan inútiles; salvo que esperemos hacer del empresario un santo o de las leyes mercantiles un catecismo omnicomprensivo con poderes absolutos.

17 M. SANDEL, Justicia. ¿Hacemos lo que debemos?, op. cit., 284.

18 Resalté algunas de estas cosas en el prólogo al libro Valores, derechos y Estado a finales del siglo XX, op. cit., 9 y ss. 